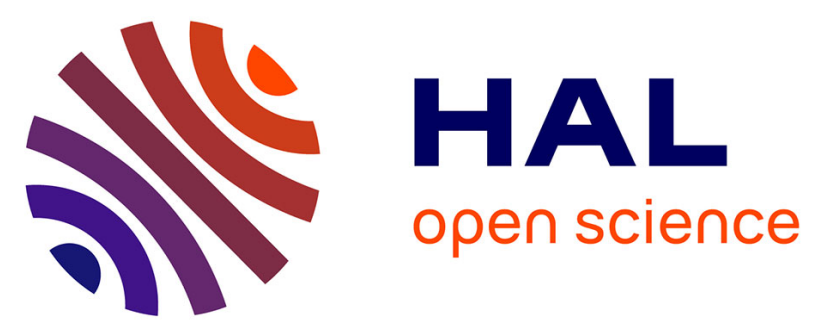

\title{
C75 is converted to C75-CoA in the hypothalamus, where it inhibits carnitine palmitoyltransferase 1 and decreases food intake and body weight
}

Paula Mera, Assia Bentebibel, Eduardo López-Viñas, Antonio G. Cordente, Chandrashekaran Gurunathan, David Sebastián, Irene Vázquez, Laura

Herrero, Xavier Ariza, Paulino Gómez-Puertas, et al.

\section{To cite this version:}

Paula Mera, Assia Bentebibel, Eduardo López-Viñas, Antonio G. Cordente, Chandrashekaran Gurunathan, et al.. C75 is converted to $\mathrm{C} 75-\mathrm{CoA}$ in the hypothalamus, where it inhibits carnitine palmitoyltransferase 1 and decreases food intake and body weight. Biochemical Pharmacology, 2009, 77 (6), pp.1084. 10.1016/j.bcp.2008.11.020 . hal-00531844

\section{HAL Id: hal-00531844 \\ https://hal.science/hal-00531844}

Submitted on 4 Nov 2010

HAL is a multi-disciplinary open access archive for the deposit and dissemination of scientific research documents, whether they are published or not. The documents may come from teaching and research institutions in France or abroad, or from public or private research centers.
L'archive ouverte pluridisciplinaire HAL, est destinée au dépôt et à la diffusion de documents scientifiques de niveau recherche, publiés ou non, émanant des établissements d'enseignement et de recherche français ou étrangers, des laboratoires publics ou privés. 


\section{Accepted Manuscript}

Title: $\mathrm{C} 75$ is converted to $\mathrm{C} 75-\mathrm{CoA}$ in the hypothalamus, where it inhibits carnitine palmitoyltransferase 1 and decreases food intake and body weight

Authors: Paula Mera, Assia Bentebibel, Eduardo López-Viñas, Antonio G. Cordente, Chandrashekaran

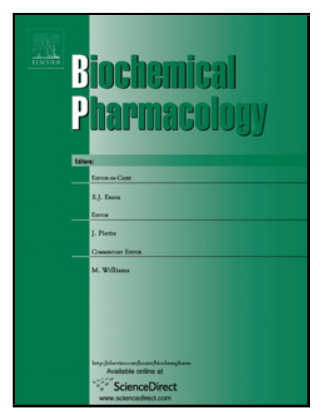

Gurunathan, David Sebastián, Irene Vázquez, Laura Herrero, Xavier Ariza, Paulino Gómez-Puertas, Guillermina Asins, Dolors Serra, Jordi García, Fausto G. Hegardt

$\begin{array}{ll}\text { PII: } & \text { S0006-2952(08)00855-1 } \\ \text { DOI: } & \text { doi:10.1016/j.bcp.2008.11.020 } \\ \text { Reference: } & \text { BCP } 10024\end{array}$

To appear in: $\quad B C P$

Received date: $\quad 16-10-2008$

Revised date: $\quad 12-11-2008$

Accepted date: $\quad$ 20-11-2008

Please cite this article as: Mera P, Bentebibel A, López-Viñas E, Cordente AG, Gurunathan C, Sebastián D, Vázquez I, Herrero L, Ariza X, Gómez-Puertas P, Asins G, Serra D, García J, Hegardt FG, C75 is converted to C75-CoA in the hypothalamus, where it inhibits carnitine palmitoyltransferase 1 and decreases food intake and body weight, Biochemical Pharmacology (2008), doi:10.1016/j.bcp.2008.11.020

This is a PDF file of an unedited manuscript that has been accepted for publication. As a service to our customers we are providing this early version of the manuscript. The manuscript will undergo copyediting, typesetting, and review of the resulting proof before it is published in its final form. Please note that during the production process errors may be discovered which could affect the content, and all legal disclaimers that apply to the journal pertain. 


\title{
$\mathrm{C} 75$ is converted to $\mathrm{C} 75-\mathrm{CoA}$ in the hypothalamus, where it inhibits carnitine palmitoyltransferase 1 and decreases food intake and body weight
}

\author{
Paula Mera ${ }^{1,2 \dagger}$, Assia Bentebibel $^{1 \dagger}$, Eduardo López-Viñas ${ }^{2,3}$, Antonio G. \\ Cordente $^{1}$, Chandrashekaran Gurunathan ${ }^{1}$, David Sebastián ${ }^{1}$, Irene Vázquez ${ }^{1}$, \\ Laura Herrero ${ }^{1,2}$, Xavier Ariza ${ }^{4}$, Paulino Gómez-Puertas ${ }^{2,3}$, Guillermina Asins ${ }^{1,2}$, \\ Dolors Serra $^{1,2}$, Jordi García ${ }^{4}$, and Fausto G. Hegardt ${ }^{1,2 *}$
}

${ }^{1}$ Department of Biochemistry and Molecular Biology and IBUB (Institute of Biomedicine University of Barcelona), ${ }^{2}$ CIBER "Fisiopatología de la Obesidad y la Nutrición" (CB06/03), Instituto de Salud Carlos III, School of Pharmacy, University of Barcelona, E-08028 Barcelona, Spain, ${ }^{3}$ Centro de Biología Molecular "Severo Ochoa" (CSIC-UAM), Cantoblanco, E-28049 Madrid, Spain, ${ }^{4}$ Department of Organic Chemistry and IBUB, School of Chemistry, University of Barcelona, E-08028 Barcelona, Spain.

${ }^{\dagger}$ Both authors contributed equally to this study

*Corresponding author: Prof. Fausto G. Hegardt

Phone: +34934024523 / Fax: +34934024520

E-mail: fgarciaheg@ub.edu 
RUNNING TITLE: Hypothalamic inhibition of CPT1 by C75-CoA.

\begin{abstract}
ABBREVIATIONS: ARC, arcuate nucleus; CPT, carnitine palmitoyltransferase; CrAT, carnitine acetyltransferase; FAS, fatty acid synthase;; wt, wild-type.
\end{abstract}

KEYWORDS: Fatty acid metabolism, anti-obesity drugs, C75, CPT1 carnitine palmitoyltransferase, FAS fatty acid synthase. 


\begin{abstract}
Central nervous system administration of C75 produces hypophagia and weight loss in rodents identifying $\mathrm{C} 75$ as a potential drug against obesity and type 2 diabetes. However, the mechanism underlying this effect is unknown. Here we show that C75CoA is generated chemically, in vitro and in vivo from $\mathrm{C} 75$ and that it is a potent inhibitor of carnitine palmitoyltranferase 1 (CPT1), the rate-limiting step of fatty acid oxidation. Three-D docking and kinetic analysis support the inhibitory effect of C75CoA on CPT1. Central nervous system administration of $\mathrm{C} 75$ in rats led to C75-CoA production, inhibition of CPT1 and lower body weight and food intake. Our results suggest that inhibition of CPT1, and thus increased availability of fatty acids in the hypothalamus, contribute to the pharmacological mechanism of C75 to decrease food intake.
\end{abstract}




\section{Introduction}

The brain plays an important role in the evaluation and control of energy homeostasis. Blood concentrations of glucose and fatty acids are sensed by neurons of the hypothalamus, which adjusts feeding behaviour and monitors fatty-acid metabolism. Several laboratories have attempted to design anti-obesity drugs and modulate fatty acid metabolism to inhibit food intake. C75 is a synthetic inhibitor of fatty acid synthase (FAS) [1] and has been proposed as an anti-obesity agent since its administration decreases food intake and body weight in rodents [2-5]. C75 can alter the metabolism of neurons in the hypothalamus, where an increase in the level of malonyl-CoA due to FAS inhibition serves as a secondary messenger of nutrient status, thereby mediating the suppression of food intake [6,7]. Hypothalamic levels of long-chain fatty acyl-CoA (LCFA-CoA) also signal nutrient availability and control food intake [8].

Malonyl-CoA signals the availability of lipid and carbohydrate fuels [9] and acts as a physiological inhibitor of the enzyme carnitine palmitoyltransferase 1 (CPT1). CPT1 catalyzes the first step in the transport of LCFA from the cytoplasm to the mitochondria, and is the rate-limiting step in $\beta$-oxidation. Mammalian tissues express three CPT1 isoforms: CPT1A, CPT1B and CPT1C which differ in their sensitivity to malonyl-CoA and tissue distribution $[10,11]$. CPT1A and CPT1C are expressed in the brain. CPT1A is located in the mitochondrial membrane and CPT1C is expressed in the endoplasmic reticulum of neurons where although it has CPT1 activity, it does not participate in mitochondrial fatty-acid oxidation [12]. Interestingly, our group has generated a mutant form of CPT1A insensitive to malonyl-CoA (CPT1A M593S), and a mutant form of carnitine acetyltransferase (CrAT) that swaps its preference from short to LCFA-CoA (CrAT D356A/M564G). These mutants have allowed us to examine the structural requirements of substrates and inhibitors [13-15]. 
The inhibition of FAS by $\mathrm{C} 75$ produces an accumulation of malonyl-CoA which is difficult to reconcile with the activation of CPT1 reported by others [2, 16-18]. To unravel this paradox the mechanism of action of $\mathrm{C} 75$ needs to be examined. We recently demonstrated that $\mathrm{C} 75$ is converted in vitro to $\mathrm{C} 75-\mathrm{CoA}$, a potent inhibitor of CPT1 [19]. CPT1 activity was also inhibited in mitochondria from pancreas-, muscle-, and kidney-derived cell lines incubated with $\mathrm{C} 75$, which indicates that $\mathrm{C} 75-\mathrm{CoA}$ is produced in these cells. This inhibition was followed by a decrease in fatty-acid oxidation. The role of CPT1 in heart, liver and pancreatic $\beta$-cells makes it a potential target in the treatment of diabetes, obesity, and other human diseases.

Here we show that C75-CoA, and not C75, directly inhibits CPT1 activity. We also show that C75-CoA is formed in the hypothalamus in a dose-dependent way, where it inhibits CPT1 activity and decreases food intake and body weight. These results indicate that direct inhibition of CPT1 by C75-CoA in the hypothalamus could control body weight and feeding behaviour. 


\section{Materials and methods}

\subsection{Materials}

L- $\left[\right.$ methyl $\left.-{ }^{3} \mathrm{H}\right]$ carnitine hydrochloride was purchased from Amersham Biosciences (GE Healthcare, Europe, Barcelona, Spain). Yeast culture media products were from Difco ${ }^{\mathrm{TM}}$ Laboratories (Detroit, MI). Bradford solution for protein assays was from Bio-Rad Laboratories (Barcelona, Spain). RPMI 1640 was from Gibco-Invitrogen Corporation (Barcelona, Spain). C75, $\mathrm{C}_{17-\mathrm{CoA}}$, defatted bovine serum albumin (BSA), palmitoylCoA, malonyl-CoA, and other chemicals were from Sigma-Aldrich (Madrid, Spain). Acyl-CoA synthetase from Pseudomonas sp. was from Sigma (Madrid, Spain). Etomoxir was provided by H.P.O. Wolf (GMBH, Allensbach, Germany).

\subsection{Animals}

Sprague-Dawley female rats (210-230 g) were bred in our laboratory. Animals were maintained under a $12 \mathrm{~h}$ dark/light cycle with free access to food (2014, Harlan) and water. All experimental protocols were approved by the Animal Ethics Committee at the University of Barcelona, in accordance with current legislation.

\subsection{Cannulation surgery}

Chronic (i.c.v.) cannulae were stereotaxically implanted into lateral ventricle under ketamine (Imalgene, $90 \mathrm{mg} / \mathrm{Kg}$ ) and xylazine (Rompun, $11 \mathrm{mg} / \mathrm{Kg}$ ) anesthesia. The coordinates were: $1.0 \mathrm{~mm}$ posterior to bregma, $1.4 \mathrm{~mm}$ lateral of the sagittal sinus and $6.2 \mathrm{~mm}$ ventral to the dura mater. Rats received subcutaneous injection of buprenorphine $(0.05 \mathrm{mg} / \mathrm{Kg})$ for analgesia. 


\subsection{Stereotaxic microinjection}

Rats were anesthetized as previously described and immobilized in a stereotaxic apparatus. Injections were given bilaterally into the ARC nucleus of the hypothalamus (2.7 $\mathrm{mm}$ posterior to bregma, $0.2 \mathrm{~mm}$ lateral of the sagittal sinus and $9.8 \mathrm{~mm}$ ventral to the dura mater). 30 minutes after the injection rats were sacrificed and hypothalamus was dissected.

\subsection{Treatments}

After 1 week of postsurgical recovery, cannula placements were verified by assessing a feeding response to ghrelin [20]. I.c.v. injection (5 $\mu \mathrm{l})$ of etomoxir $(190 \mu \mathrm{g}), \mathrm{C} 75$ (40 $\mu \mathrm{g}$ ) or vehicle (RMPI 1640) were performed with a microliter syringe (Hamilton). For feeding experiments, rats received single injections of vehicle or compound dissolved in vehicle $30 \mathrm{~min}$ before the light was turned off. We measured intakes of chow, corrected for spillage, at 1, 2, 4 and $22 \mathrm{~h}$. Body weight was measured after $22 \mathrm{~h}$. For the activity experiments 3 rats were microinjected (ARC) with $2 \mu \mathrm{L}$ of RPMI 1640 medium as a control or with $2 \mu \mathrm{L}$ of $\mathrm{C} 75$ dissolved in the same medium at $33 \mathrm{mM}$ final concentration. For the LC-MS/MS analysis, 2 rats were microinjected (ARC) with $2 \mu \mathrm{L}$ of RPMI 1640 medium as control or with $2 \mu \mathrm{L}$ of C75 dissolved in the same medium at 15,30 or $60 \mathrm{mM}$ final concentration. 30 minutes after injection rats were killed and hypothalamus was excised and stored at $-80^{\circ} \mathrm{C}$ for acyl-CoA extraction.

\subsection{C75-CoA and acyl-CoAs extraction and quantification}

Acyl-CoAs were extracted as described elsewhere [21], with some modifications. All procedures were performed at 0-4 ${ }^{\circ} \mathrm{C}$. Hypothalamus from control- and $\mathrm{C} 75-$ microinjected rats was thawed and $1 \mathrm{~mL}$ of $100 \mathrm{mM} \mathrm{KH}_{2} \mathrm{PO}_{4} \mathrm{pH} 4.9$ was added. 16 
nmol of heptadecanoyl-CoA $\left(\mathrm{C}_{17}-\mathrm{CoA}\right)$, as an internal standard, was added to all samples, which were then sonicated for 20 s. One millilitre of n-propanol was added and the emulsions were sonicated for a further $20 \mathrm{~s}$, left on ice for $20 \mathrm{~s}$, and sonicated again for 20s. To this solution, $0.125 \mathrm{~mL}$ of saturated $\left(\mathrm{NH}_{4}\right)_{2} \mathrm{SO}_{4}$ was added, followed by 2 $\mathrm{mL}$ of $100 \%$ acetonitrile, and the mixture was then vortexed for $5 \mathrm{~min}$ at $4{ }^{\circ} \mathrm{C}$. The tubes were then centrifuged for $5 \mathrm{~min}$ at $2,100 \mathrm{xg}$ at $4{ }^{\circ} \mathrm{C}$. The supernatant was removed and passed through a sterile $0.2 \mu \mathrm{m}$ filter (Millipore). The filtrate was lyophilized and re-dissolved in the same mobile phase (buffer B: $10 \%$ acetonitrile in $10 \mathrm{mM}$ ammonium acetate buffer ( $\mathrm{pH}$ 5.3)) used for the LC-MS/MS analysis. $\mathrm{C}_{17}-\mathrm{CoA}$ and $\mathrm{C} 75-\mathrm{CoA}$ were used as standards to produce the calibration curves from which we quantified production of C75-CoA in vivo. The straight lines obtained had a regression coefficient of $99 \%$.

\subsection{Liquid chromatography-mass spectrometry (LC-MS/MS)}

LC analyses were performed using a Perkin Elmer series 200 equipped with a quaternary pump and thermostatted autosampler. An XBridge (Waters) $\mathrm{C}_{18}$ column (50 x $2.1 \mathrm{~mm}, 3.5 \mu \mathrm{m}$ ) was used at room temperature and the volume injected was $15 \mu \mathrm{L}$. The mobile phases were buffer A, 50\% acetonitrile in $10 \mathrm{mM}$ ammonium acetate buffer ( $\mathrm{pH} 5.3$ ); buffer $\mathrm{B}, 10 \%$ acetonitrile in $10 \mathrm{mM}$ ammonium acetate buffer ( $\mathrm{pH} 5.3$ ) and C, $100 \%$ acetone. The column was equilibrated with $15 \%$ buffer A for $10 \mathrm{~min}$, and then the eluting gradient was as follows: $15 \%$ buffer A to $90 \%$ buffer A in $5.5 \mathrm{~min}$, then $90 \%$ buffer $\mathrm{A}$ to $50 \%$ buffer $\mathrm{A}, 5 \% \mathrm{C}$ to $45 \% \mathrm{C}$ in $15.5 \mathrm{~min}$, and $50 \%$ buffer $\mathrm{A}, 45 \% \mathrm{C}$ in 25 min. The flow rate was $0.4 \mathrm{~mL} / \mathrm{min}$.

MS and MS/MS experiments were performed on an API 3000 triple-quadrupole mass spectrometer equipped with a Turbo Ionspray source. All the analyses were performed 
in positive mode with the following settings: capillary voltage, $+3000 \mathrm{~V}$; nebulizer gas $\left(\mathrm{N}_{2}\right), 10$ (arbitrary units); curtain gas $\left(\mathrm{N}_{2}\right), 12$ (arbitrary units); collision gas $\left(\mathrm{N}_{2}\right), 4$ (arbitrary units); declustering potential, $+30 \mathrm{~V}$; focusing potential, $+200 \mathrm{~V}$; entrance potential, $+10 \mathrm{~V}$; collision energy, $+40 \mathrm{~V}$; collision cell exit potential, $+15 \mathrm{~V}$. Drying gas $\left(\mathrm{N}_{2}\right)$ was heated to $300{ }^{\circ} \mathrm{C}$ and introduced at a flow-rate of $6000 \mathrm{~cm}^{3} \mathrm{~min}^{-1}$. Full scan data acquisition was performed scanning from $\mathrm{m} / \mathrm{z} 500$ to 1200 in profile mode and using a cycle time of $2 \mathrm{~s}$ with a step size of $0.1 \mathrm{u}$ and a pause between each scan of 2 ms. In order to achieve maximum sensitivity, samples were injected in multiple reaction monitoring mode (MRM) by monitoring the $1022.5 / 515.6$ and the $1020.7 / 513.5$ transitions, obtained through product ion scan experiments with the $\mathrm{C} 75-\mathrm{CoA}$ and $\mathrm{C}_{17^{-}}$ CoA standard, respectively. To calculate the C75-CoA concentration in the samples, 15 $\mu \mathrm{L}$ of increasing concentrations of $\mathrm{C} 75-\mathrm{CoA}$ and $\mathrm{C}_{17-} \mathrm{CoA}$ from 10 to $5000 \mathrm{nM}$ was injected. The areas of the resulting peaks were used to produce the calibration curve. The $\mathrm{C}_{17}-\mathrm{CoA}$ was used as internal standard to calculate the percentage of recovery in the acyl-CoA extraction.

\subsection{Enzymatic synthesis of C75-CoA and etomoxiryl-CoA}

C75 was converted first, in vitro, to its CoA derivative by long-chain acyl-CoA synthetase in the presence of CoA, as described previously [19]. The unreacted CoA from the C75-CoA activation solution $(1 \mathrm{~mL})$ was removed by incubation for $30 \mathrm{~min}$ at $4{ }^{\circ} \mathrm{C}$ with $1.25 \mathrm{~mL}$ of SulfoLink Coupling Gel (Pierce Biotechnology), as carnitine acyltransferase activity is inhibited by CoA [22]. C75-CoA synthesized in this enzymatic reaction was used as a standard for LC-MS/MS analysis. The conversion of etomoxir to etomoxiryl-CoA was nearly complete, as deduced from the fluorometric assay of the remaining free CoA, as described elsewhere [23]. 


\subsection{Non-enzymatic synthesis of C75-CoA}

In the second experiment, a solution of $\mathrm{C} 75$ and $\mathrm{CoA}(\mathrm{pH} \mathrm{8.4)}$ was stirred in the absence of acyl-CoA synthetase. The structure and relative stereochemistry of the C75CoA adduct was determined by NMR. CoA sodium salt hydrate $(8.6 \mathrm{mg})$, and $\mathrm{Na}_{3} \mathrm{PO}_{4} \cdot 12 \mathrm{H}_{2} \mathrm{O}(7.6 \mathrm{mg})$ were added to a solution of $( \pm)-\mathrm{C} 75(2.5 \mathrm{mg})$ in $\mathrm{D}_{2} \mathrm{O}(0.8 \mathrm{~mL})$ in an NMR tube. The structure of the C75-CoA adduct was fully determined by ${ }^{1} \mathrm{H}$ and ${ }^{13} \mathrm{C}$ NMR, gCOSY and gHSQC experiments.

\subsection{Expression of rat CrAT and CPT1 in Saccharomyces cerevisiae}

Plasmids pYESCrAT ${ }^{\mathrm{wt}}$ [14], pYESCrAT ${ }^{\mathrm{D} 356 \mathrm{~A} / \mathrm{M} 564 \mathrm{G}}$ [15], pYESLCPT $^{\mathrm{wt}}$ [24], pYESLCPT $^{\mathrm{M} 593 \mathrm{~S}}$ [13] containing CrAT wt, CrAT D356A/M564G mutant, CPT1A wt and CPT1A M593S mutant, respectively, were expressed in yeast cells, and mitochondrial cell extracts were prepared as previously described [24]. An S. cerevisiae strain devoid of COT and CPT1 activity and lacking the endogenous CAT2 gene (FY23 $\triangle$ cat2 (MATa trp1 ura3 $\Delta c a t 2:: L E U 2))$ was used as an expression system [25].

\subsection{Determination of carnitine acyltransferase activity}

Mitochondrial-enriched fractions were obtained by differential centrifugation [26], with minor modifications. All protein concentrations were determined using the Bio-Rad protein assay with bovine serum albumin as a standard.

Two methods were used for the assay of carnitine acyltransferase: a radiometric method [24] and an endpoint fluorometric method [14, 23]. The radiometric assay was used in all cases, unless otherwise indicated. Radiometric method: The forward reaction of carnitine acyltransferase activity was assayed in mitochondrial-enriched fractions obtained from yeast $(5 \mu \mathrm{g}$ protein for CrAT D356A/M564G and 3-4 $\mu \mathrm{g}$ protein for 
CPT1A) and from rat hypothalamus (100 $\mu \mathrm{g}$ protein for CPT1). Enzyme activity was assayed for $4 \mathrm{~min}$ at $30^{\circ} \mathrm{C}$ in a total volume of $200 \mu \mathrm{L}$. The substrates were $400 \mu \mathrm{M} \mathrm{L}$ $\left[\right.$ methyl $\left.{ }^{3} \mathrm{H}\right]$ carnitine, and $50 \mu \mathrm{M}$ myristoyl-CoA (for $\mathrm{CrAT}$ D356A/M564G) or palmitoyl-CoA (for CPT1A). Drugs were preincubated with the enzyme for 1-5 min depending on the assay. Drug concentrations ranging from 0.01 to $60 \mu \mathrm{M}$ were used to calculate the $\mathrm{IC}_{50}$. Enzyme assays were carried out to deduce the effects of the free acid (C75) versus the CoA ester (C75-CoA), that is, the potency of $\mathrm{C} 75-\mathrm{CoA}$ as inhibitor relative to $\mathrm{C} 75$ as an activator. In this case, CPT1A wt overexpressed in yeast $(8 \mu \mathrm{g}$ protein) was preincubated for 5 min with increasing concentrations of C75 (5-100 $\mu \mathrm{M})$, C75-CoA $(5-50 \mu \mathrm{M})$ with or without $100 \mu \mathrm{M}$ C75 at each C75-CoA concentration. Enzyme activity was compared to the control (DMSO). In all cases, the molar ratio of acyl-CoA to albumin was kept at 5:1 to avoid the presence of free acyl-CoA and its deleterious detergent effects and to prevent the formation of micelles. Fluorometric method: The forward reaction of carnitine acyltransferase activity was assayed for $8 \mathrm{~min}$ at $30{ }^{\circ} \mathrm{C}$ in a solution containing $0.1 \mathrm{mM}$ acyl-CoA, $1.5 \mathrm{mM}$ EDTA, $1.5 \mathrm{mM}$ Lcarnitine, and $40 \mathrm{mM}$ Hepes buffer, $\mathrm{pH} 7.8$, in a total volume of $600 \mu \mathrm{L}$. Acetyl-CoA was used as substrate for CrAT wt. Reactions were started by the addition of $5 \mu \mathrm{g}$ of yeast-expressed protein. Increasing concentrations of C75-CoA, etomoxiryl-CoA or malonyl-CoA were independently incubated with yeast-overexpressed mitochondrial CrAT wt. Parallel (blank) assays were run in the absence of L-carnitine.

\subsection{Construction of rat CrAT and CPT1A models}

A model of rat CrAT wt enzyme was constructed by homology modelling using as templates the structures deposited in the Protein Data Bank (PDB) corresponding to human (1NM8) [27], and mouse CrAT (1NDB, 1NDF and 1NDI) [28], essentially as 
described elsewhere [14]. CrAT D356A/M564G was modelled by the same procedures using rat $\mathrm{CrAT}$ wt as template. CPT1A was also modelled using as templates the structures of mouse carnitine octanoyltransferase (1XL7, 1XL8) [29] and carnitine palmitoyltransferase 2 (PDB entry 2H4T) [30], essentially as described elsewhere [31, 32]. The quality of the models was checked using the WHAT-CHECK routines [33] from the WHAT-IF program [34] and the PROCHECK validation program from the SWISS-MODEL server facilities [35]. To optimize geometries and release local constraints or inappropriate contacts, the modelled structures were energy minimized with the implementation of the GROMOS 43B1 force field in the program DeepView [36], using 500 steps of steepest descent minimization followed by 500 steps of conjugate-gradient minimization.

\subsection{In Silico molecular docking}

Structural models of the molecular docking of the inhibitors C75-CoA and malonylCoA to the active site of the receptor proteins CPT1A, and CrAT mutant D356A/M564G were performed using the suite of programs included in the Autodock 3.0 package [35], as described elsewhere [14].

\subsection{Statistical analysis}

Data are represented as mean \pm S.E.M. Student $t$-test was used for statistical analysis. Different experimental groups were compared with a one-way ANOVA followed by Turkey's test for comparisons post hoc. A probability level of $P<0.05$ was considered significant. 


\section{Results}

\subsection{Synthesis and chemical characterization of C75-CoA by NMR}

We have shown that C75-CoA can be synthesized from C75 and CoA in the presence of acyl-CoA synthetase from Pseudomonas sp. [19]. Here we show that the MS spectrum of $\mathrm{C} 75-\mathrm{CoA}$ gave an $[\mathrm{M}+\mathrm{H}]^{+}$ion at $m / z$ 1022.5, corresponding to the protonated molecule of C75-CoA. This ion corresponded to the formation of the C75-CoA molecule by conjugation of the CoA group without the loss of a water molecule. The product showed the following: a fragmentation ion at $m / z 515.6$, which was assigned to the C75-pantethenoic group, and an ion at $\mathrm{m} / \mathrm{z} 428.1$, which corresponds to adenosine 3'-diphosphate (Supplemental Fig. S1).

We hypothesised that the - SH group in CoA would be sufficiently nucleophilic to add to the electrophilic methylene group in C75 without any external agent (acyl-CoA synthetase) in an alkaline medium in which the thiol group is partially deprotonated. We mixed both reagents, $\mathrm{C} 75$ and $\mathrm{HSCoA}$ in a deuterated water solution at $\mathrm{pH} 8.4$ (Fig. 1A) and the mixture was analyzed by ${ }^{1} \mathrm{H}$ NMR, comparing the results with the unreacted C75 and CoA. The peaks assigned to the methylene group (black triangle) progressively decreased and a new signal at $\sim 2.9 \mathrm{ppm}$ appeared due to the formation of the new saturated methylene group (white triangle) (Fig.1B). These changes were fast (30 min). In a parallel experiment at neutral $\mathrm{pH}$ the same transformation was observed, albeit much more slowly (data not shown).

The structure and relative stereochemistry of the C75-CoA adduct shown in Figure 1C were determined by one- and two-dimensional ${ }^{1} \mathrm{H}$ and ${ }^{13} \mathrm{C}$ NMR techniques in order to assign every signal (gCOSY and gHSQC experiments) [37]. In particular, the transtrans relative configuration on the lactone ring shown in the Figure $1 \mathrm{C}$ is well 
established on the basis of the observed coupling constants $(J)$, especially $J_{d, e}$. These coupling constants depend on the dihedral angle (H-C-C-H) of the protons involved and give information about their relative position. When we compared the coupling constants of the lactone ring moiety of our adduct with those reported $[38,39]$ for the related compounds I and II (Fig. 1C) high correlation with II was observed, suggesting the same relative configuration.

As described above, we used two methods to obtain C75-CoA. In one, a solution of C75 and CoA was incubated in the presence of acyl-CoA synthetase. In the other, the adduct was synthesised in the absence of the enzyme. We aimed to determine whether the structural and inhibitory properties of the C75-CoA adducts depended on the presence of acyl-CoA synthetase in their synthesis. Two analytical tests were applied. First, a comparative mass/mass spectroscopy analysis showed that the C75-CoA synthesised in the presence of the enzyme (Supplemental Fig. S1) had the same ion fragmentation profile as that synthesised in the absence of the enzyme (data not shown). Second, we assayed their capacity to inhibit CPT1, obtaining identical results for both adducts (Fig. 1D). We conclude that the two adducts synthesized in the presence or absence of the enzyme have identical structure and properties.

\subsection{Effect of C75 and C75-CoA on CPT1 activity}

To examine the controversial effect of C75 on CPT1 activity we incubated yeast mitochondria with increased concentrations of C75 (Fig. 2A). The results reported indicate that free $\mathrm{C} 75$ alone is neither an activator nor an inhibitor of CPT1. We also performed kinetic inhibitory experiments in which, in addition to increasing concentrations of C75-CoA, a fixed concentration of C75 $(100 \mu \mathrm{M})$ was added to the mixture. CPT1 inhibition was not counteracted by the fixed amount of free C75 at any 
concentration of C75-CoA. In other words, even at the highest $\mathrm{C} 75$ concentrations, the free product did not overcome the inhibition by C75-CoA (Fig. 2B).

\subsection{Inhibitory effects of C75-CoA on yeast-expressed mutated CPT1A and CrAT}

To examine the structural requirements of the interaction between $\mathrm{C} 75-\mathrm{CoA}$ and CPT1 we carried out C75-CoA inhibitory experiments where we used specific acyltransferase mutants. We used CrAT D356A/M564G, which has a deep hydrophobic pocket for the binding of LCFA-CoAs instead of short acyl-CoAs and behaves like CPT1A in terms of acyl-CoA specificity [15]. We also used CPT1A M593S, which is active but insensitive to malonyl-CoA inhibition [13]. Experiments with etomoxiryl-CoA, a pharmacological inhibitor of CPT1, and malonyl-CoA, its physiological inhibitor, were carried out as controls.

C75-CoA and etomoxiryl-CoA inhibited CrAT D356A/M564G but had little effect on CrAT wt (Fig. 3A and 3B). At $60 \mu \mathrm{M}$ of C75-CoA, the remaining CrAT activity was $83 \%$ for CrAT wt, and only $21 \%$ of the original level for CrAT D356A/M564G. For etomoxiryl-CoA, at a concentration of $60 \mu \mathrm{M}$, the remaining activity was $86 \%$ for CrAT wt, and $46 \%$ for the CrAT mutant. These results indicate that CrAT wt is insensitive to these drugs because the long aliphatic chain of C75-CoA and etomoxiryl-CoA does not fit in the shallow cavity of the wt enzyme, where only the acyl group of short-chain acyl-CoAs such as acetyl- and butiryl-CoA can enter. However, when this cavity was open and accessible to longer acyl-CoAs, as in the CrAT D356A/M564G mutant, the enzyme became sensitive to these inhibitors. In contrast, malonyl-CoA had little effect on mutant or wt CrAT (Fig. 3A and 3B). These results show that CrAT D356A/M564G, like the wt enzyme, does not contain the structural determinants needed for the initial interaction with malonyl-CoA and enzyme inhibition. 
Next we compared the inhibitory effect of C75-CoA on CPT1A wt and CPT1A M593S. At $50 \mu \mathrm{M}$ of $\mathrm{C} 75-\mathrm{CoA}$, the remaining activity of the M593S mutant was about $45 \%$ of the original level (Fig. 3D), whereas the activity of the CPT1A wt was almost abolished (Fig. 3C). A similar effect was observed with etomoxiryl-CoA. Malonyl-CoA, as expected, inhibited CPT1A wt while the activity of the malonyl-CoA-insensitive enzyme (CPT1A M593S) was unaffected. The $\mathrm{IC}_{50}$ for C75-CoA and CPT1A M593S was 108-fold higher than that for CPT1A wt $(25.9 \mu \mathrm{M}$ vs. $0.24 \mu \mathrm{M})$. In the case of etomoxiryl-CoA the $\mathrm{IC}_{50}$ increased 31-fold compared with the wt enzyme (168 $\mu \mathrm{M} v s$.

4.1 $\mu \mathrm{M})$. This indicates that CPT1A inhibitors in addition to fitting in the hydrophobic pocked also need to interact with the malonyl-CoA site of CPT1A to produce potent inhibition.

\subsection{Molecular model of docking of C75-CoA into CPT1A wt, and CrAT D356A/M564G}

Since CPT1 has not yet been crystallized, we do not know the location of C75-CoA in the CPT1 crystal. Therefore, we used computational docking methods to identify a putative location of $\mathrm{C} 75-\mathrm{CoA}$ molecule in the 3-D models of the catalytic core of CPT1A wt and of CrAT D356A/M564G. The model locates the C75-CoA molecule (Fig. 4A) in CTP1A wt in a position that coincides with the site of palmitoyl-CoA substrate [32], thus introducing the aliphatic chain into the hydrophobic cavity in the protein active centre. The carboxyl group in the head of the C75-CoA molecule is positioned at the equivalent locus for the carnitine substrate in the CPT1A wt models, partially filling it. This indicates that this inhibitor could hamper the correct positioning of the carnitine substrate. Moreover, the head of C75-CoA is also located near the catalytic His residue $\left(\mathrm{His}^{473}\right)$, which would impair the catalytic activity of CPT1A. The 
position of the carboxyl group on C75-CoA (Fig. 4A) is similar to that proposed for the dicarbonyl moiety of malonyl-CoA on CPT1A [32], which thus interferes with the correct positioning of carnitine substrate (Fig. 4C). This shared mode of action could be explained in part by the presence of a carboxyl group in carnitine, C75-CoA and malonyl-CoA molecules (Fig. 4D), putatively located in the active centre of the enzyme. An analogous model was constructed for the location of C75 in CrAT D356A/M564G mutant structure. The position of the $\mathrm{C} 75$ aliphatic chain moiety is similar to that proposed for stearoyl-CoA in the same enzyme derivative [15], in which the hydrocarbon chain is located in the cavity that opens up when $\mathrm{Asp}^{356}$ and $\mathrm{Met}^{564}$ are replaced by Ala and Gly respectively (Fig. 4B). The carboxyl group at the head of C75 is located in the carnitine locus, close to the catalytic $\mathrm{His}^{343}$ residue as mentioned above for CPT1A.

\section{5. $\mathrm{C} 75$ is converted to $\mathrm{C} 75-\mathrm{CoA}$ in rat hypothalamus}

Since C75 has been proposed as a regulator of food intake through its action on the hypothalamus, we examined whether $\mathrm{C} 75-\mathrm{CoA}$ is produced in the hypothalamus following direct injection of C75. We injected 7.6, 15.2 and $30.4 \mu \mathrm{g}$ of $\mathrm{C} 75$ in the arcuate (ARC) nucleus by stereotaxic surgery. Thirty minutes after injection the rats were killed and acyl-CoAs, including C75-CoA, were extracted from the hypothalamus. Analysis of the samples by LC-MS/MS showed a peak corresponding to C75-CoA (Fig. 5). The production of $\mathrm{C} 75-\mathrm{CoA}$ increased with the amount of $\mathrm{C} 75$ injected. Considering that in our conditions the average weight of the rat hypothalamus was $50 \mathrm{mg}$, the concentrations of $\mathrm{C} 75-\mathrm{CoA}$ produced in the hypothalamus after an injection of 7.6, 15.2 and $30.4 \mu \mathrm{g}$ of $\mathrm{C} 75$ were $3.7,15.9$ and $25.1 \mathrm{nmol} / \mathrm{g}$ tissue respectively. 
3.6. Central nervous system administration of C75 inhibits CPT1 activity and decreases food intake and body weight

Having demonstrated the conversion of $\mathrm{C} 75$ into $\mathrm{C} 75-\mathrm{CoA}$ in the rat hypothalamus, we then studied the effect of a stereotaxic microinjection of $\mathrm{C} 75$ into the rat ARC nucleus on CPT1 activity. Hypothalamic mitochondrial fractions from rats injected with $16.8 \mu \mathrm{g}$ of C75 were assayed for CPT1 activity and the value was compared to hypothalamic mitochondrial fractions from rats injected with RPMI medium. Activity was decreased by $46 \%$ in $\mathrm{C} 75$-treated rats (Fig. $6 \mathrm{~A}$ ).

Next we administered C75 in the lateral cerebral ventricle of the rat and measured food intake and body weight. Consistent with previous results [2-5], C75 produced a decrease in food intake and body weight (Fig. 6B and 6C). The anorectic action of etomoxir was seen at a later point (22h). 


\section{Discussion}

Energy balance is monitored by the hypothalamus, where inhibitors of FAS have been described to suppress food intake [40, 41]. C75 acts on fatty acid metabolism by inhibiting FAS activity. Inhibition of FAS produces accumulation of malonyl-CoA, which, as a physiological inhibitor of CPT1, prevents the oxidation of newly synthesized fatty acids. Moreover, C75 may activate CPT1 $[2,18]$. The effect of C75 on FAS is difficult to reconcile with the C75-activation of CPT1 as they have opposite effects: inhibition by malonyl-CoA and direct activation of CPT1. The simultaneous activation and inhibition of CPT1 by C75 appears paradoxical, and it has not been addressed satisfactorily. Kuhajda et al. suggested that $\mathrm{C} 75$ could modulate the inhibition of AMP-activated protein kinase (AMPK) which would lead to an increase in acetylCoA carboxylase (ACC) activity and a subsequent increase in malonyl-CoA levels [42]. This does not solve the paradox, since there would be an increase in malonyl-CoA (putatively inhibiting CPT1 activity) and a simultaneous activation of CPT1 produced by C75 itself (Fig. 7).

Here we attempt to explain the anorectic effects of C75 in terms of its inhibitory action on CPT1. Inhibition of CPT1 could prevent the oxidation of fatty acids of the ARC nucleus in the hypothalamus leading to a local accumulation of LCFA-CoAs. The increase in LCFA-CoA is a central signal of 'nutrient abundance' which in turn activates a chain of neuronal events, via up-regulation of anorexigenic genes and down regulation of orexigenic genes, that would promote a switch in fuel sources from carbohydrates to lipids and limit food intake [8]. The detailed mechanism of this up- or down-regulation has not been addressed yet. Likewise, central administration of fatty acid suppresses food intake. Here we demonstrated that C75 is transformed into C75- 
CoA in the hypothalamus where it inhibits CPT1 activity. We propose that this direct effect in vivo of C75-CoA on CPT1 would explain by itself the inhibition of CPT1 activity. However, FAS could be inhibited by C75 in the hypothalamus. Therefore, malonyl-CoA could be in excess, inhibiting CPT1, together with C75-CoA. The anorectic effects of C75 are similar to those produced by other CPT1 inhibitors such as ST1326 and tetradecylglycidic acid, and to those of a riboprobe that specifically cleaves CPT1A mRNA [8]. The CPT1 inhibitor etomoxir also decreased feeding and reduced body weight in rats supporting those previous results [8].

It was important to discern whether C75 was an inhibitor or an activator of CPT1. Our results indicate that $\mathrm{C} 75$ is neither an activator nor an inhibitor of CPT1 when incubated with yeast-expressed CPT1A. C75 did not overcome the inhibition caused by C75-CoA. This agrees with the observed net effect of inhibition of CPT1 activity. Results shown here and elsewhere [19] demonstrate that C75-CoA inhibits CPT1A in vitro more strongly than etomoxiryl-CoA ( $\mathrm{IC}_{50}$ values are $0.24 \mu \mathrm{M}$ and $4.1 \mu \mathrm{M}$ respectively).

The finding that $\mathrm{C} 75$ forms a CoA ester before it can inhibit CPT1 is reminiscent of the case of etomoxir. McGarry and co-workers [43, 44] showed that the CPT1 inhibitory molecules were neither tetradecylglycidic acid nor etomoxir themselves, but rather their CoA esters produced in the presence of acyl-CoA synthetase. The CoA group may direct and fix the drug molecule in the cavities of CPT1, as it does with the natural physiological inhibitor malonyl-CoA and with the substrate palmitoyl-CoA. The synthesis of C75-CoA is produced stereo specifically through the electrophilic methylene group of $\mathrm{C} 75$. Moreover, our finding that $\mathrm{C} 75-\mathrm{CoA}$ is produced in absence of acyl-CoA synthetase indicated that it could be synthesised in the hypothalamus, irrespective of whether it is expressed in hypothalamic neurons. 
Our results indicate that $\mathrm{C} 75-\mathrm{CoA}$ is formed in the hypothalamus following stereotaxic injection of C75. Inhibition of hypothalamic CPT1 by C75-CoA in vivo, as seen in our experiments, is independent of the putative inhibition by malonyl-CoA, which may be formed after the action of C75 either on FAS or on AMPK. Hypothalamic CPT1 activity was determined in twice-washed mitochondria. Therefore, malonyl-CoA was unlikely to remain within $\mathrm{CPT} 1$, as this metabolite leaves CPT1 freely when mitochondria are washed. In contrast, $\mathrm{C} 75-\mathrm{CoA}$, as it is a tight-binding inhibitor, remains bound to the enzyme after washing, which means that its inhibition is persistent [19]. Hence, C75-CoA not only inhibits CPT1 in vitro, but it also inhibits CPT1 activity in the hypothalamus after $\mathrm{C} 75$ has been converted to its CoA derivative.

That C75-CoA is an inhibitor of CPT1A is also supported by the docking analysis of the CPT1A model. Comparison of computer-calculated docking models shows that CoA is bound at the same site, whether it belongs to C75-CoA or malonyl-CoA, or palmitoylCoA. The carboxylic acid bound to the lactone of $\mathrm{C} 75$ protrudes into the carnitine site. The inhibitory mechanism of C75-CoA resembles that observed for malonyl-CoA (Fig. 4C) [32]. Several authors reported the competition between malonyl-CoA and carnitine $[45,46]$. The carboxylate group of malonyl-CoA and C75-CoA may partially mimic the interaction between the enzyme and the carboxylate group of carnitine, thus preventing the positioning of this substrate and inhibiting the catalytic activity of the enzyme. Several authors [47, 48] suggest that the presence of two carbonyl groups in close juxtaposition in the malonyl-CoA molecule might be responsible for the interaction and the inhibitory effect on CPT1A. Because C75-CoA also has these two carbonyl groups, it may behave like malonyl-CoA. Indeed the docking models show that C75-CoA could bind to the malonyl-CoA site of the enzyme [32]. 
Moreover, the hydrocarbon chain of $\mathrm{C} 75$ is located at the same site as the hydrocarbon long-chain of palmitic acid. The kinetic experiments of inhibition of C75-CoA against palmitoyl-CoA [19] are confirmed by the docking studies, and both support the notion that $\mathrm{C} 75-\mathrm{CoA}$ is a strong inhibitor of CPT1A.

To assess the involvement of the hydrocarbon chain of C75-CoA positioning in the acyl group binding pocket, we carried out $\mathrm{C} 75-\mathrm{CoA}$ inhibitory experiments with the new mutated protein, CrAT D356A/M564G. This protein has a deep hydrophobic pocket for the binding of long-chain instead of short-chain acyl-CoAs and shows CPT1-like behaviour in terms of acyl-CoA specificity, although unlike CPT1A, it is not inhibited by malonyl-CoA [15]. The inhibition by C75-CoA of the mutant CrAT D356A/M564G suggests that $\mathrm{C} 75-\mathrm{CoA}$ fits in the large hydrophobic pocket of this enzyme, as in CPT1A wt, and that the presence of this pocket is necessary for C75-CoA inhibition. However, CrAT D356A/M564G is not as sensitive as CPT1A wt to C75-CoA, since the $\mathrm{IC}_{50}$ for $\mathrm{C} 75-\mathrm{CoA}$ acting on CPT1A wt is 50-fold lower than that observed for the CrAT double mutant. These results indicate that factors other than the presence of a hydrophobic pocket contribute to the inhibitory potency of C75-CoA toward CPT1. CPT1A M593S, which is insensitive to malonyl-CoA inhibition, shows limited sensitivity towards $\mathrm{C} 75-\mathrm{CoA}$, but its $\mathrm{IC}_{50}$ for $\mathrm{C} 75-\mathrm{CoA}$ is similar to that of $\mathrm{CrAT}$ double mutant (25.9 vs. $12.8 \mu \mathrm{M}$, respectively). Therefore, the lack of a "malonyl-CoAlike" interaction between CrAT double mutant or CPT1A M593S and the carbonyl groups in the polar head of C75-CoA might explain their limited sensitivity to the inhibitor.

We conclude that C75 is converted into C75-CoA and that it strongly inhibits CPT1 in vitro and in vivo. Docking and kinetic analysis revealed the molecular basis by which C75-CoA interacts with the enzyme and its substrates. We also show that C75-CoA is 
formed in vivo in the hypothalamus, where it inhibits CPT1. Here the inhibition of CPT1 could alter fatty acid oxidation, thus putatively promoting down-regulation of orexigenic genes and up-regulation of anorexigenic genes, which induces restriction in food intake. These results point to the potential use of drugs to inhibit CPT1 activity, and control food intake in the treatment of obesity and diabetes. 


\section{REFERENCES}

[1] Kuhajda FP, Pizer ES, Li JN, Mani NS, Frehywot GL, Townsend CA. Synthesis and antitumor activity of an inhibitor of fatty acid synthase. Proc Natl Acad Sci U S A 2000;97:3450-4.

[2] Thupari JN, Landree LE, Ronnett GV, Kuhajda FP. C75 increases peripheral energy utilization and fatty acid oxidation in diet-induced obesity. Proc Natl Acad Sci U S A 2002;99:9498-502.

[3] Thupari JN, Kim EK, Moran TH, Ronnett GV, Kuhajda FP. Chronic C75 treatment of diet-induced obese mice increases fat oxidation and reduces food intake to reduce adipose mass. Am J Physiol Endocrinol Metab 2004;287:E97E104.

[4] Clegg DJ, Wortman MD, Benoit SC, McOsker CC, Seeley RJ. Comparison of central and peripheral administration of $\mathrm{C} 75$ on food intake, body weight, and conditioned taste aversion. Diabetes 2002;51:3196-201.

[5] Kumar MV, Shimokawa T, Nagy TR, Lane MD. Differential effects of a centrally acting fatty acid synthase inhibitor in lean and obese mice. Proc Natl Acad Sci U S A 2002;99:1921-5.

[6] Loftus TM, Jaworsky DE, Frehywot GL, Townsend CA, Ronnett GV, Lane MD, et al. Reduced food intake and body weight in mice treated with fatty acid synthase inhibitors. Science 2000;288:2379-81.

[7] $\mathrm{Hu} \mathrm{Z}$, Cha SH, Chohnan S, Lane MD. Hypothalamic malonyl-CoA as a mediator of feeding behavior. Proc Natl Acad Sci U S A 2003;100:12624-9.

[8] Obici S, Feng Z, Arduini A, Conti R, Rossetti L. Inhibition of hypothalamic carnitine palmitoyltransferase-1 decreases food intake and glucose production. Nat Med 2003;9:756-61.

[9] McGarry JD, Brown NF. The mitochondrial carnitine palmitoyltransferase system. From concept to molecular analysis. Eur J Biochem 1997;244:1-14.

[10] Esser V, Brown NF, Cowan AT, Foster DW, McGarry JD. Expression of a cDNA isolated from rat brown adipose tissue and heart identifies the product as the muscle isoform of carnitine palmitoyltransferase I (M-CPT I). M-CPT I is the predominant CPT I isoform expressed in both white (epididymal) and brown adipocytes. J Biol Chem 1996;271:6972-7.

[11] Price N, van der Leij F, Jackson V, Corstorphine C, Thomson R, Sorensen A, et al. A novel brain-expressed protein related to carnitine palmitoyltransferase I. Genomics 2002;80:433-42.

[12] Sierra AY, Gratacos E, Carrasco P, Clotet J, Urena J, Serra D, et al. CPT1c is localized in endoplasmic reticulum of neurons and has carnitine palmitoyltransferase activity. J Biol Chem 2008;283:6878-85.

[13] Morillas M, Gomez-Puertas P, Bentebibel A, Selles E, Casals N, Valencia A, et al. Identification of conserved amino acid residues in rat liver carnitine palmitoyltransferase I critical for malonyl-CoA inhibition. Mutation of methionine 593 abolishes malonyl-CoA inhibition. J Biol Chem 2003;278:905863.

[14] Cordente AG, Lopez-Vinas E, Vazquez MI, Swiegers JH, Pretorius IS, GomezPuertas $\mathrm{P}$, et al. Redesign of carnitine acetyltransferase specificity by protein engineering. J Biol Chem 2004;279:33899-908. 
[15] Cordente AG, Lopez-Vinas E, Vazquez MI, Gomez-Puertas P, Asins G, Serra D, et al. Mutagenesis of specific amino acids converts carnitine acetyltransferase into carnitine palmitoyltransferase. Biochemistry 2006;45:6133-41.

[16] Nicot C, Napal L, Relat J, Gonzalez S, Llebaria A, Woldegiorgis G, et al. C75 activates malonyl-CoA sensitive and insensitive components of the CPT system. Biochem Biophys Res Commun 2004;325:660-4.

[17] Aja S, Bi S, Knipp SB, McFadden JM, Ronnett GV, Kuhajda FP, et al. Intracerebroventricular C75 decreases meal frequency and reduces AgRP gene expression in rats. Am J Physiol Regul Integr Comp Physiol 2006;291:R148-54.

[18] Aja S, Landree LE, Kleman AM, Medghalchi SM, Vadlamudi A, McFadden $\mathrm{JM}$, et al. Pharmacological stimulation of brain carnitine palmitoyl-transferase-1 decreases food intake and body weight. Am J Physiol Regul Integr Comp Physiol 2008;294:R352-61.

[19] Bentebibel A, Sebastian D, Herrero L, Lopez-Vinas E, Serra D, Asins G, et al. Novel effect of C75 on carnitine palmitoyltransferase I activity and palmitate oxidation. Biochemistry 2006;45:4339-50.

[20] Lopez M, Lelliott CJ, Tovar S, Kimber W, Gallego R, Virtue S, et al. Tamoxifen-induced anorexia is associated with fatty acid synthase inhibition in the ventromedial nucleus of the hypothalamus and accumulation of malonylCoA. Diabetes 2006;55:1327-36.

[21] Golovko MY, Murphy EJ. An improved method for tissue long-chain acyl-CoA extraction and analysis. J Lipid Res 2004;45:1777-82.

[22] Zierz S, Engel AG. Different sites of inhibition of carnitine palmitoyltransferase by malonyl-CoA, and by acetyl-CoA and $\mathrm{CoA}$, in human skeletal muscle. Biochem J 1987;245:205-9.

[23] Hassett RP, Crockett EL. Endpoint fluorometric assays for determining activities of carnitine palmitoyltransferase and citrate synthase. Anal Biochem 2000;287:176-9.

[24] Morillas M, Gomez-Puertas P, Roca R, Serra D, Asins G, Valencia A, et al. Structural model of the catalytic core of carnitine palmitoyltransferase I and carnitine octanoyltransferase (COT): mutation of CPT I histidine 473 and alanine 381 and COT alanine 238 impairs the catalytic activity. J Biol Chem 2001;276:45001-8.

[25] Swiegers JH, Dippenaar N, Pretorius IS, Bauer FF. Carnitine-dependent metabolic activities in Saccharomyces cerevisiae: three carnitine acetyltransferases are essential in a carnitine-dependent strain. Yeast 2001;18:585-95.

[26] Rickwood D, Graham JM. Subcellular fractionation : a practical approach. Oxford: IRL Press at Oxford University Press, 1997.

[27] Wu D, Govindasamy L, Lian W, Gu Y, Kukar T, Agbandje-McKenna M, et al. Structure of human carnitine acetyltransferase. Molecular basis for fatty acyl transfer. J Biol Chem 2003;278:13159-65.

[28] Jogl G, Tong L. Crystal structure of carnitine acetyltransferase and implications for the catalytic mechanism and fatty acid transport. Cell 2003;112:113-22.

[29] Jogl G, Hsiao YS, Tong L. Crystal structure of mouse carnitine octanoyltransferase and molecular determinants of substrate selectivity. J Biol Chem 2005;280:738-44.

[30] Hsiao YS, Jogl G, Esser V, Tong L. Crystal structure of rat carnitine palmitoyltransferase II (CPT-II). Biochem Biophys Res Commun 2006;346:97480 . 
[31] Morillas M, Lopez VE, Valencia A, Serra D, Gomez-Puertas P, Hegardt FG, et al. Structural model of carnitine palmitoyltransferase I based on the carnitine acetyltransferase crystal. Biochem J 2004;379:777-84.

[32] Lopez-Vinas E, Bentebibel A, Gurunathan C, Morillas M, de Arriaga D, Serra $\mathrm{D}$, et al. Definition by functional and structural analysis of two malonyl-CoA sites in carnitine palmitoyltransferase 1A. J Biol Chem 2007;282:18212-24.

[33] Hooft RW, Vriend G, Sander C, Abola EE. Errors in protein structures. Nature 1996;381:272.

[34] Vriend G. WHAT IF: a molecular modeling and drug design program. J Mol Graph 1990;8:52-6, 29.

[35] Goodsell DS, Morris GM, Olson AJ. Automated docking of flexible ligands: applications of AutoDock. J Mol Recognit 1996;9:1-5.

[36] Guex N, Peitsch MC. SWISS-MODEL and the Swiss-PdbViewer: an environment for comparative protein modeling. Electrophoresis 1997;18:271423.

[37] d'Ordine R, Paneth P, Anderson VE. 13C NMR and 1H-1H NOEs of CoenzymeA: Conformation of the pantoic acid moitiety. Bioorg Chem 1995;23:169-81.

[38] Amador M, Ariza X., García J. A versatile stereoselective approach to paraconic acids Heterocycles 2006:705-20.

[39] Ariza X, García J, López M, Montserrat L. A concise synthesis of (-)methylenoactocin and (-)-Phaseolinic acid from (6S,9S)-tetradec-7-yne-6,9-diol. Synlett 2001:120-2.

[40] Shimokawa T, Kumar MV, Lane MD. Effect of a fatty acid synthase inhibitor on food intake and expression of hypothalamic neuropeptides. Proc Natl Acad Sci U S A 2002;99:66-71.

[41] Lane MD, Wolfgang M, Cha SH, Dai Y. Regulation of food intake and energy expenditure by hypothalamic malonyl-CoA. Int J Obes (Lond) 2008;32 Suppl 4:S49-54.

[42] Kuhajda FP, Landree LE, Ronnett GV. The connections between C75 and obesity drug-target pathways. Trends Pharmacol Sci 2005;26:541-4.

[43] Weis BC, Cowan AT, Brown N, Foster DW, McGarry JD. Use of a selective inhibitor of liver carnitine palmitoyltransferase I (CPT I) allows quantification of its contribution to total CPT I activity in rat heart. Evidence that the dominant cardiac CPT I isoform is identical to the skeletal muscle enzyme. J Biol Chem 1994;269:26443-8.

[44] Declercq PE, Falck JR, Kuwajima M, Tyminski H, Foster DW, McGarry JD. Characterization of the mitochondrial carnitine palmitoyltransferase enzyme system. I. Use of inhibitors. J Biol Chem 1987;262:9812-21.

[45] McGarry JD, Mills SE, Long CS, Foster DW. Observations on the affinity for carnitine, and malonyl-CoA sensitivity, of carnitine palmitoyltransferase I in animal and human tissues. Demonstration of the presence of malonyl-CoA in non-hepatic tissues of the rat. Biochem J 1983;214:21-8.

[46] Bird MI, Saggerson ED. Interacting effects of L-carnitine and malonyl-CoA on rat liver carnitine palmitoyltransferase. Biochem J 1985;230:161-7.

[47] Cook GA, Mynatt RL, Kashfi K. Yonetani-Theorell analysis of hepatic carnitine palmitoyltransferase-I inhibition indicates two distinct inhibitory binding sites. J Biol Chem 1994;269:8803-7.

[48] Kashfi K, Mynatt RL, Cook GA. Hepatic carnitine palmitoyltransferase-I has two independent inhibitory binding sites for regulation of fatty acid oxidation. Biochim Biophys Acta 1994;1212:245-52. 
[49] Lopez M, Lage R, Saha AK, Perez-Tilve D, Vazquez MJ, Varela L, et al. Hypothalamic fatty acid metabolism mediates the orexigenic action of ghrelin. Cell Metab 2008;7:389-99. 


\section{Acknowledgements}

We thank Jesús Perez-Clausell from the Department of Cell Biology, School of Biology, University of Barcelona, Felipe Casanueva's group from the Department of Molecular Endocrinology and Carlos Diéguez's group from the Department of Physiology, School of Medicine, University of Santiago de Compostela for their support in stereotaxis experiments, to Olga Jaúregui from the Scientific-Technical Services of the University of Barcelona for her technical assistance in the LC-MS/ MS analysis. We also thank Biomol-Informatics SL (http://www.biomol-informatics.com) for bioinformatics consulting. This study was supported by Grant SAF2007-61926 from the Ministerio de Educación y Ciencia, Spain; by grant C3/08 from the Fondo de Investigación Sanitaria of the Instituto de Salud Carlos III; by the Activities Program among R\&D groups of the Comunidad de Madrid in Biosciences (S-BIO-0260/2006COMBACT) and by the Ajut de Suport als Grups de Recerca de Catalunya (2005SGR00733), Spain. Financial support of "Fundación Ramón Areces" to CBMSO is also acknowledged. A.G.C. and D. S. were recipients of fellowships from the University of Barcelona, and A.B. and C.G. from the Ministerio de Educación y Ciencia, Spain. 
Figure Legends

\section{Fig. 1. NMR structural studies}

(A) Incubation of a 1:1 mixture of $\mathrm{C} 75$ and $\mathrm{CoA}$ in $\mathrm{D}_{2} \mathrm{O}$ (with $10 \%$ of DMSO-d6 in order to increase the solubility of C75). Peaks assigned to the methylene group (black triangles), peaks assigned to the saturated methylene groups (white triangles). (B) ${ }^{1} \mathrm{H}$ NMR $(300 \mathrm{MHz})$ of a $\sim 1: 1$ mixture of $\mathrm{C} 75$ and $\mathrm{CoA}$ in $\mathrm{D}_{2} \mathrm{O}$ at $\mathrm{pH} \sim 8$ at time 0 min (upper panel) and ${ }^{1} \mathrm{H}$ NMR (400 MHz) of a 1:1 mixture of $\mathrm{C} 75$ and $\mathrm{CoA}$ in $\mathrm{D}_{2} \mathrm{O}$ at $\mathrm{pH}$ $\sim 8$ after 30 min (lower panel). (C) Comparison of coupling constants $(J)$ of C75-CoA adduct lactone ring with those reported early for related compounds I and II. (D) Comparison between the CPT1 inhibitory properties of C75-CoA synthesized in absence $(\bullet)$ and in presence $(\mathrm{O})$ of acyl-CoA synthetase.

Fig. 2. CPT1A wt overexpressed in yeast is inhibited by $\mathrm{C75}-\mathrm{CoA}$ in presence of C75

(A) Mitochondrial fractions from yeast overexpression CPT1A wt were preincubated for 5 min with increasing concentrations of C75 and activity was measured. (B) Comparative CPT1A wt activity of mitochondrial fractions from yeast, incubated with increasing concentrations of $\mathrm{C} 75-\mathrm{CoA}$ and in presence or absence of a fixed concentration of C75 $(100 \mu \mathrm{M})$. Data are represented as a percentage of the control value in the presence of DMSO and the results are the average of three independent experiments.

Fig. 3. Effects of malonyl-CoA, etomoxiryl-CoA and C75-CoA on the activity of yeast-expressed wt CPT1A and CrAT, and the point mutants CPT1A M593S and CrAT D356A/M564G 
Mitochondrial extracts from yeast expressing (A) CrAT wt, (C) CPT1A wt, and point mutants (B) CrAT D356A/M564G and (D) CPT1A M593S, were preincubated with increasing concentrations of malonyl-CoA $(\bullet)$, etomoxiryl-CoA (o) and C75-CoA ( $\nabla)$. Carnitine acyltransferase activity was measured, and data are expressed relative to control values in the absence of drugs $(100 \%)$ as the mean of at least two independent experiments.

Fig. 4. In silico docking of inhibitors to 3-D models for the active centres of wt CPT1A and CrAT D356A/M564G mutant

(A) Predicted docked solution for C75-CoA molecule in the active centre of wt CPT1A. Location of catalytic residue $\mathrm{His}^{473}$ is indicated. Carboxylate group of C75-CoA partially occupy the volume corresponding to the carnitine substrate molecule (magenta). (B) Putative position for C75-CoA docking solution for C75-CoA in the active centre of CrAT D356A/M564G. The aliphatic chain of the inhibitor is located in the tunnel opened by mutated residues A356 and G564. The carboxylate group of C75$\mathrm{CoA}$ is placed in the carnitine locus (magenta). Location of catalytic $\mathrm{His}^{343}$ is also indicated. (C) Docking of malonyl-CoA on CPT1A wt showing a similar positioning to C75-CoA, locating the dicarbonyl moiety in the space usually occupied by carnitine. (D) Molecular structures of malonyl-CoA, carnitine and C75-CoA, showing a similar arrangement of their corresponding carboxyl groups. Molecular representations were performed using PyMOL (DeLano Scientific, San Carlos CA).

\section{Fig. 5. Analysis of the C75-CoA levels after hypothalamic C75 injections}

(A) LC-MS/MS representative chromatograms of $\mathrm{C} 75-\mathrm{CoA}$ and $\mathrm{C}_{17}-\mathrm{CoA}$. Five concentrations of C75-CoA: 50,100, 250, 500 and $1000 \mathrm{nM}$ and seven concentrations of $\mathrm{C}_{17}-\mathrm{CoA}: 50,100,250,500,1000,2500$ and $5000 \mathrm{nM}$ were injected and the areas 
below the resulting peaks were calculated. The calibration curves are shown in insets. Representative LC chromatograms for C75-CoA obtained from rat hypothalamus after the injection in the hypothalamic ARC nucleus of $2 \mu 1$ of $\mathrm{C} 75$ at various concentrations, (B) $15 \mathrm{mM}$, (C) $30 \mathrm{mM}$ and (D) $60 \mathrm{mM}$. 30 minutes after injection rats were decapitated, and the hypothalamus was excised, immediately frozen and stored at $-80^{\circ} \mathrm{C}$. Acyl-CoAs were extracted as described in Experimental Procedures, and $\mathrm{C}_{17}-\mathrm{Co} \mathrm{A}$ was used as internal standard. Peak areas are shown in arbitrary units.

Fig. 6. Central nervous system administration of C75 inhibits CPT1 activity and decreases food intake and body weight

(A) Determination of CPT1 activity after the injection of C75 in ARC nucleus. Control injections ( $\mathrm{n}=3 ; 2 \mu \mathrm{l}$ of RPMI 1640 medium as a control, black bar). C75 injections ( $\mathrm{n}$ $=3 ; 2 \mu \mathrm{l}$ of $\mathrm{C} 7533 \mathrm{mM}$ in RPMI 1640 medium, white bar). (B) Food intake measured in rats at 1,2, 4 and 22h after i.c.v. injection of C75 (white bars), etomoxir (grey bars) and control (RPMI medium, black bars). $n=5$. (C) Body weight measured in rats at $22 \mathrm{~h}$ after i.c.v. injection of C75 (white bar), etomoxir (grey bar) and control (RPMI medium, black bar). $\mathrm{n}=5 . * \mathrm{P}<0.05$.

\section{Fig. 7. Model of action of C75 on hypothalamic fatty acid metabolism}

Energy balance is monitored by the hypothalamus. The accumulation of malonyl-CoA due to FAS-inhibition by C75 leads to a reduction in CPT1 activity. This would increase the cytosolic pool of LCFA-CoA and thus a decrease of food intake. In addition, C75 has been suggested to inhibit AMPK resulting in an activation of ACC and consequent increase of malonyl-CoA levels [42]. Here we have shown that $\mathrm{C} 75$ is converted into C75-CoA in the hypothalamus contributing to the direct inhibition of CPT1. Our 
experiments also demonstrate that other CPT1 inhibitors such as etomoxir produce similar effects decreasing food intake. On the other hand, AMPK-activators such as ghrelin [49] lead to ACC inactivation reducing malonyl-CoA levels and CPT1 inhibition. Thus, increased $\beta$-oxidation produces a reduction on LCFA-CoAs promoting food intake. 


\section{FIGURE 1}

A)

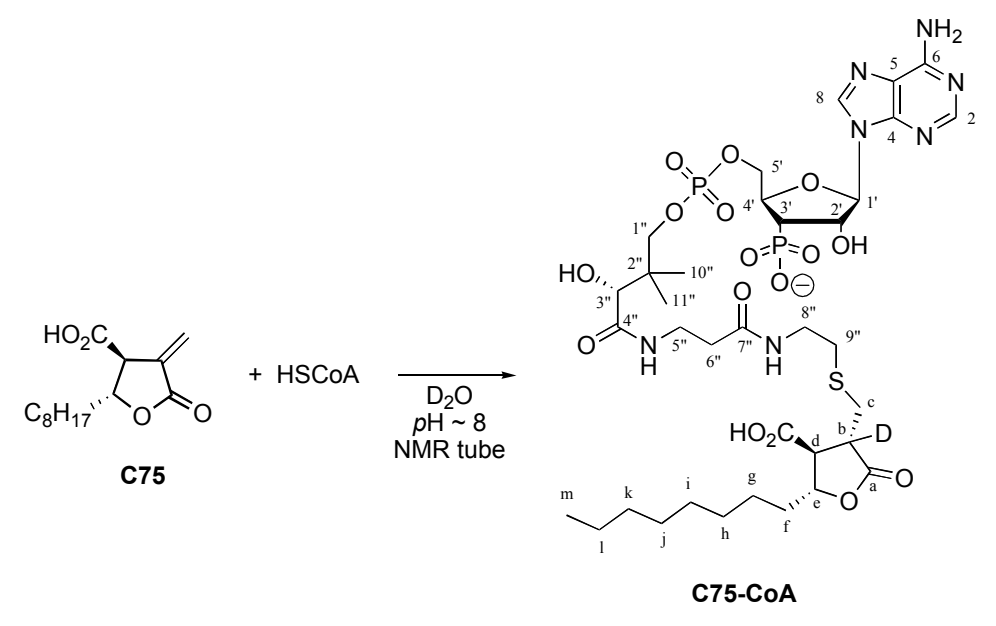

C)

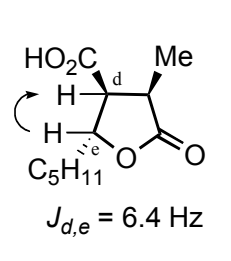

I

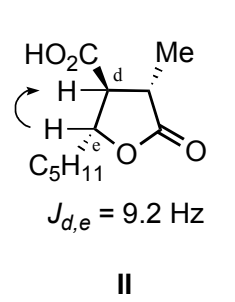

B)

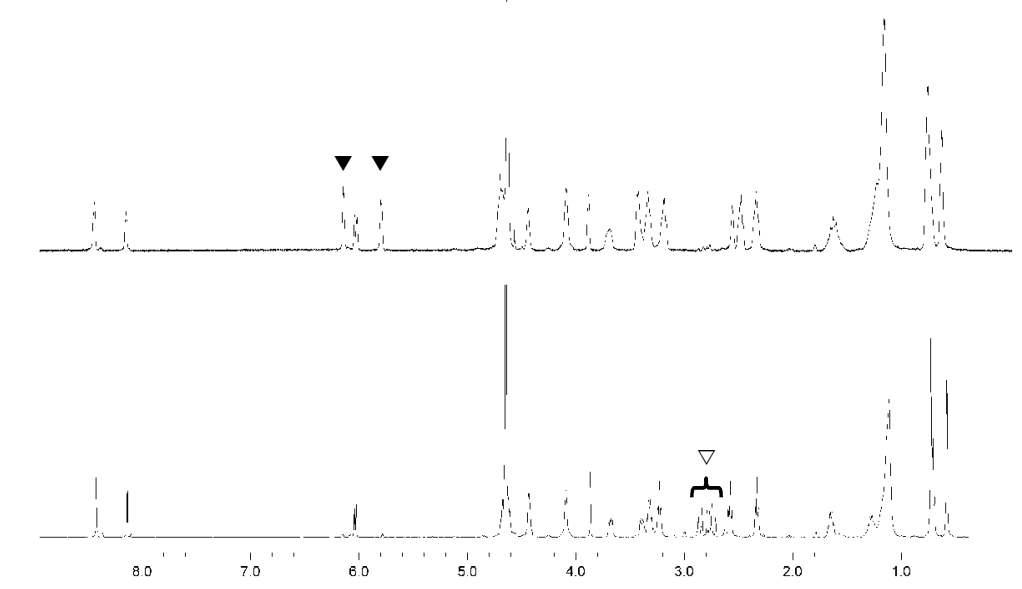

D)

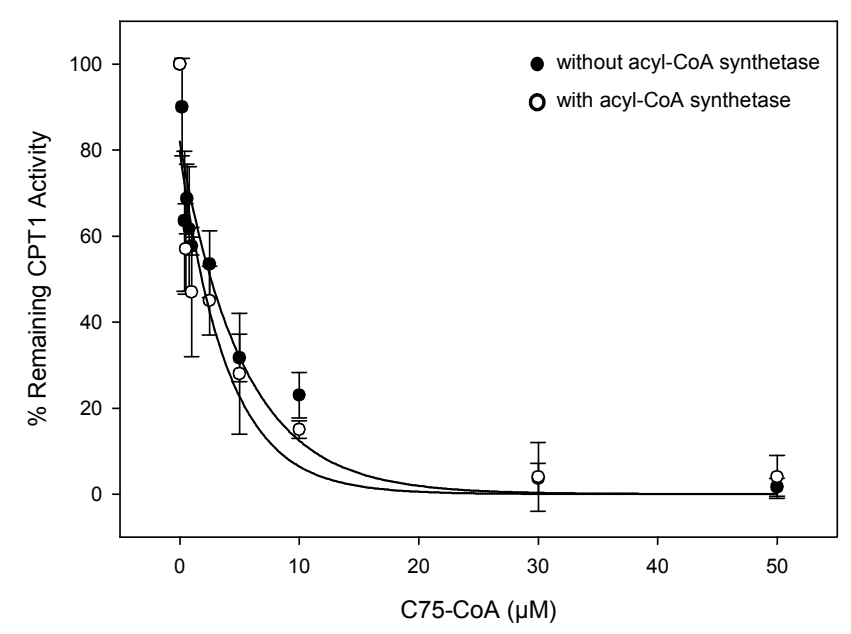




\section{FIGURE 2}

A)

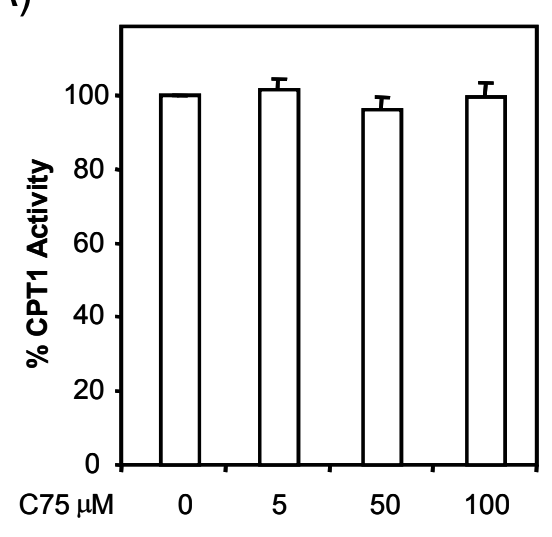

B)

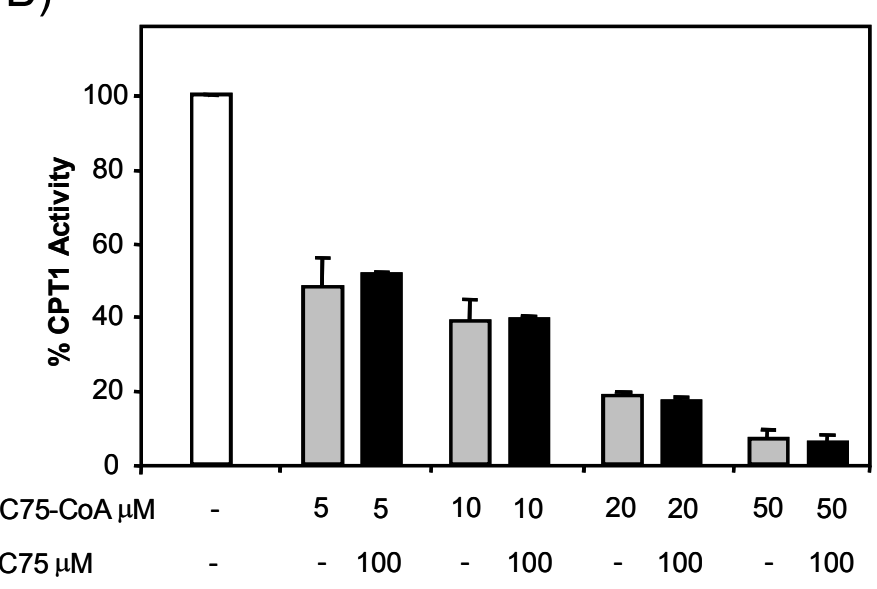




\section{FIGURE 3}
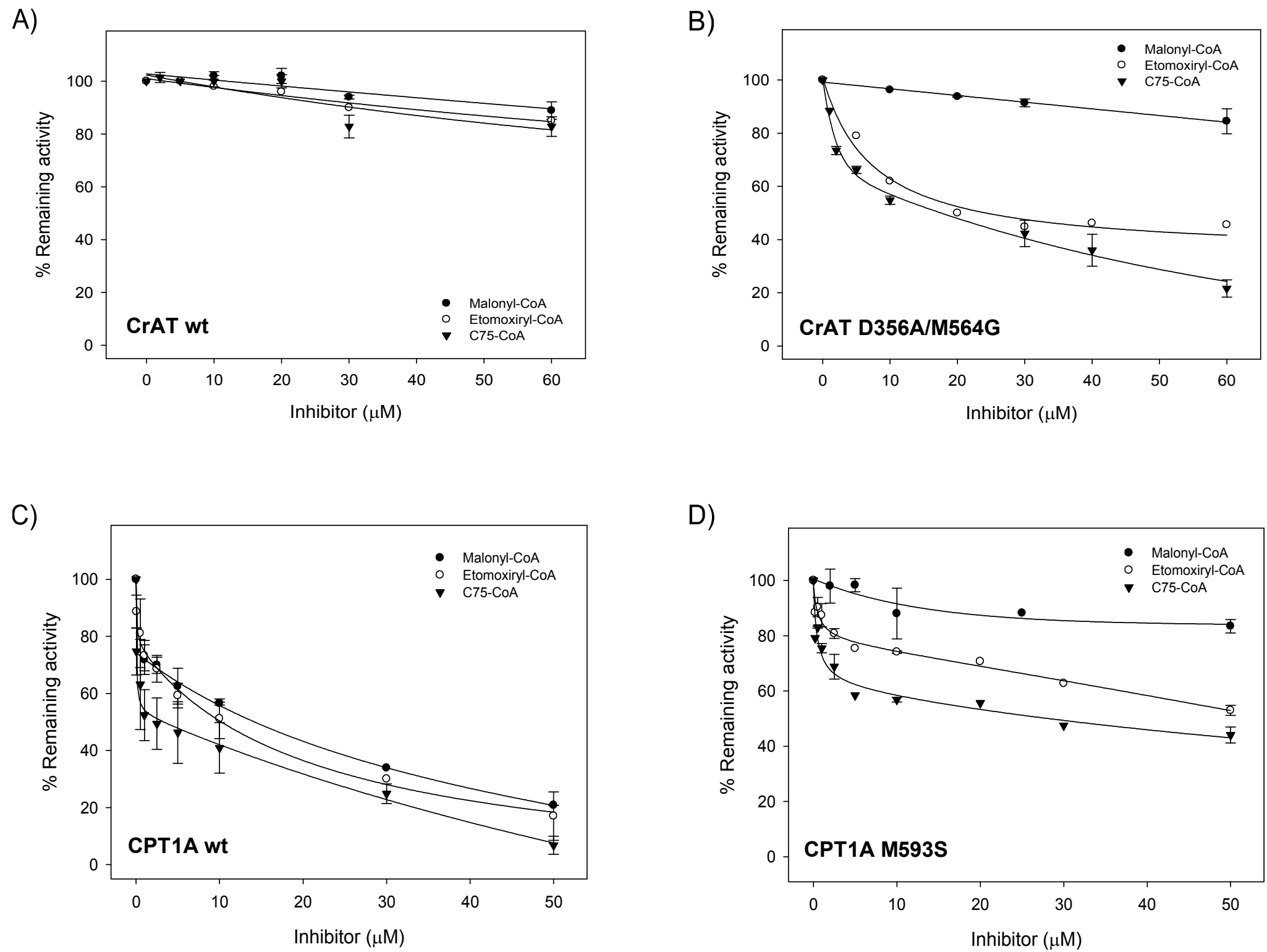


\section{FIGURE 4}
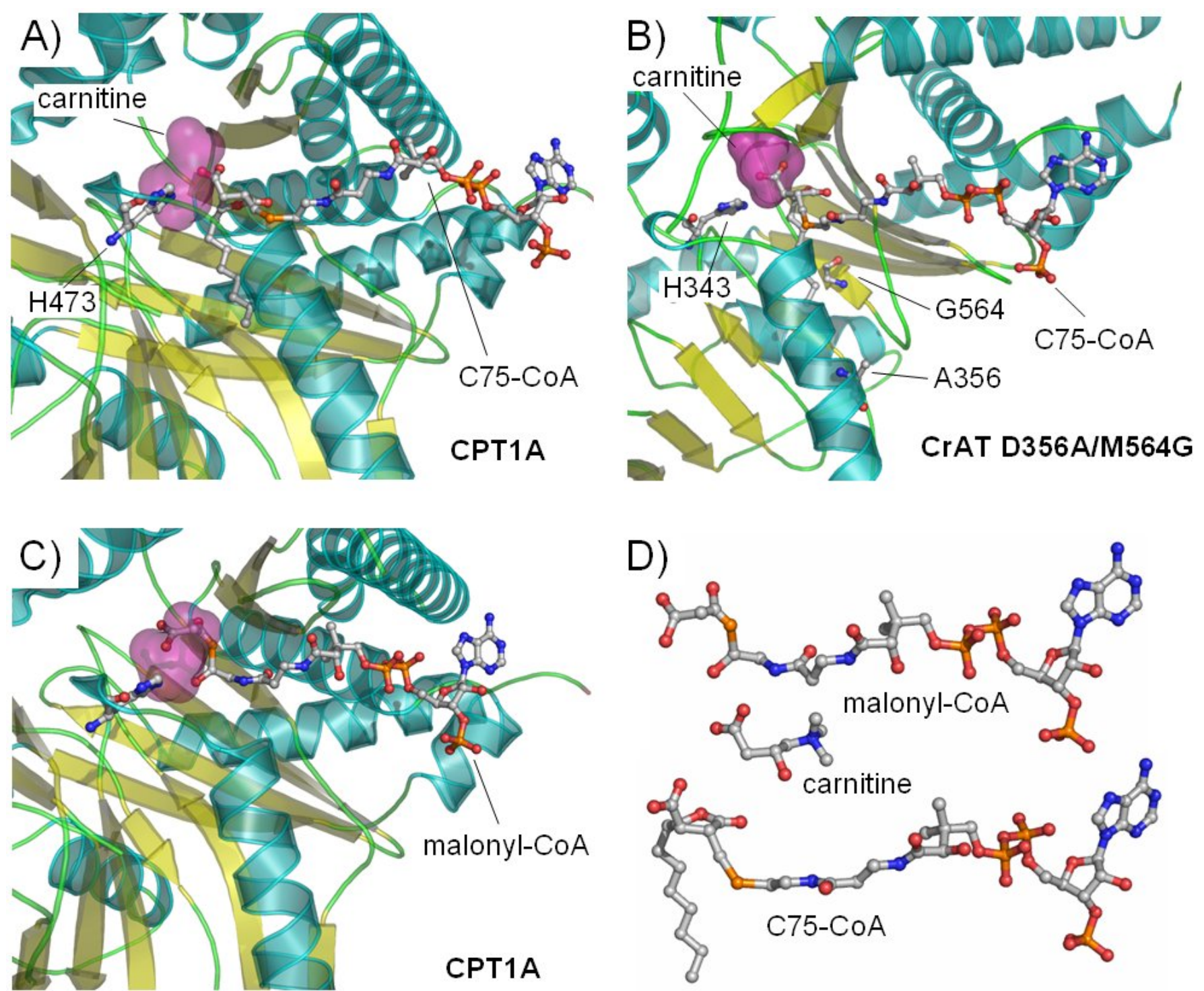


\section{FIGURE 5}

A)

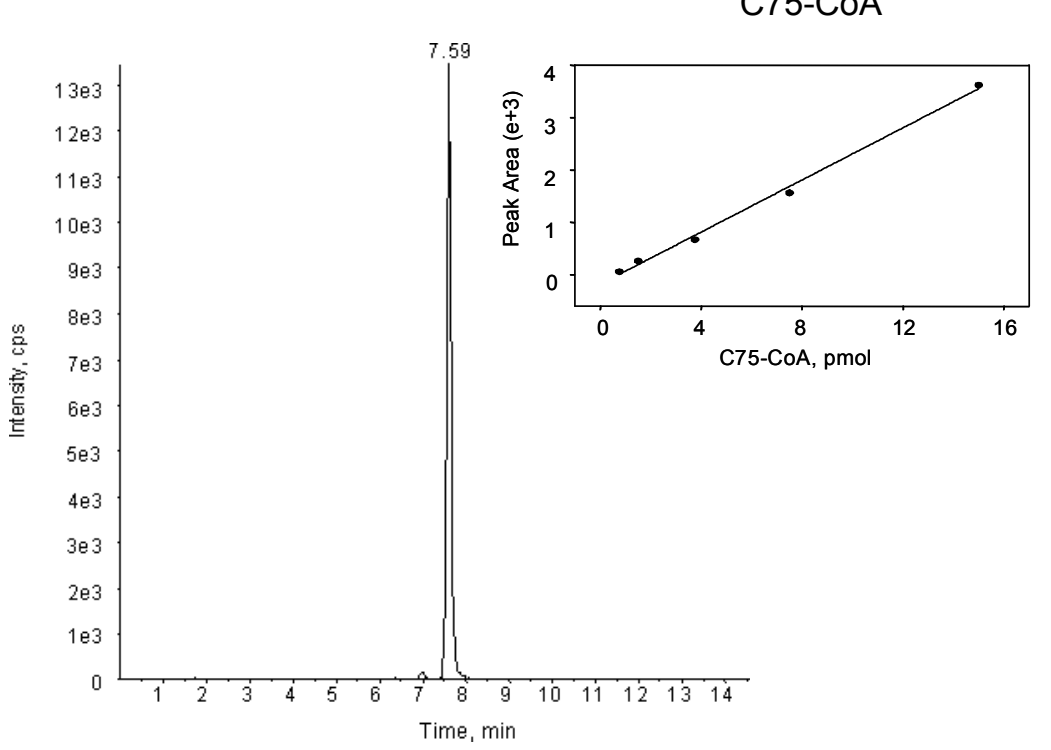

B)

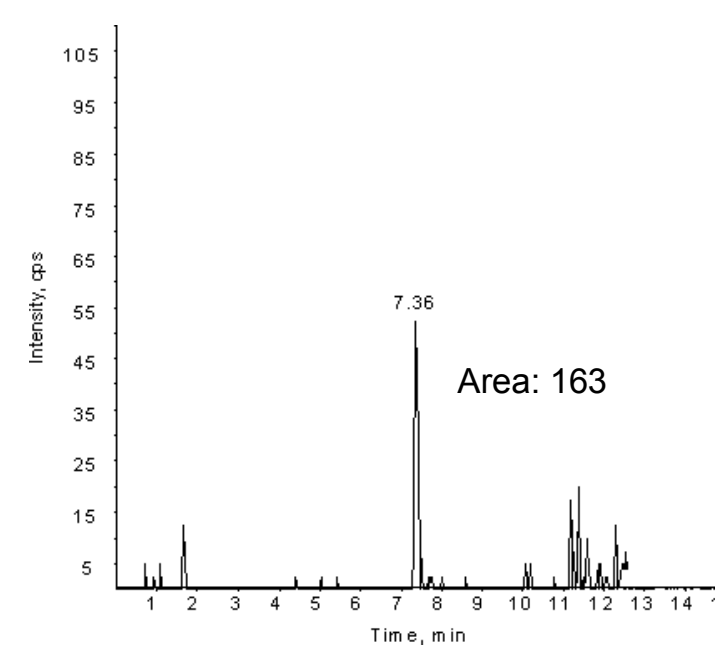

C)

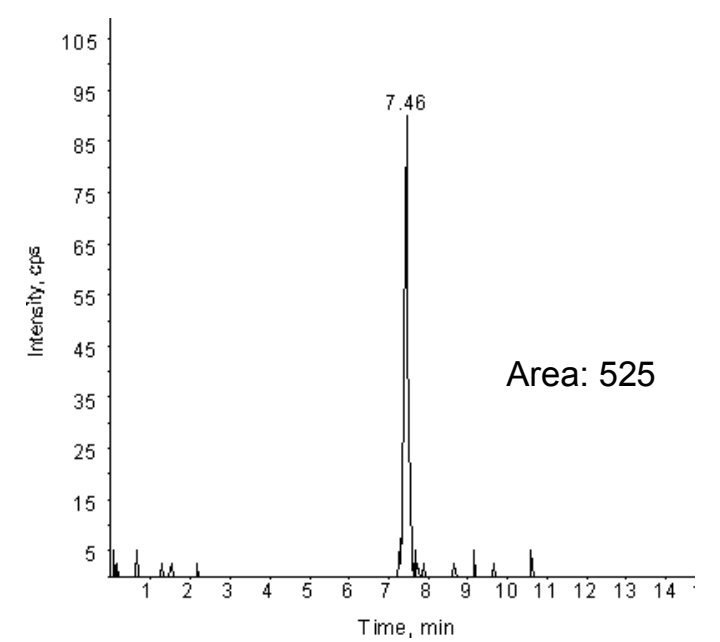

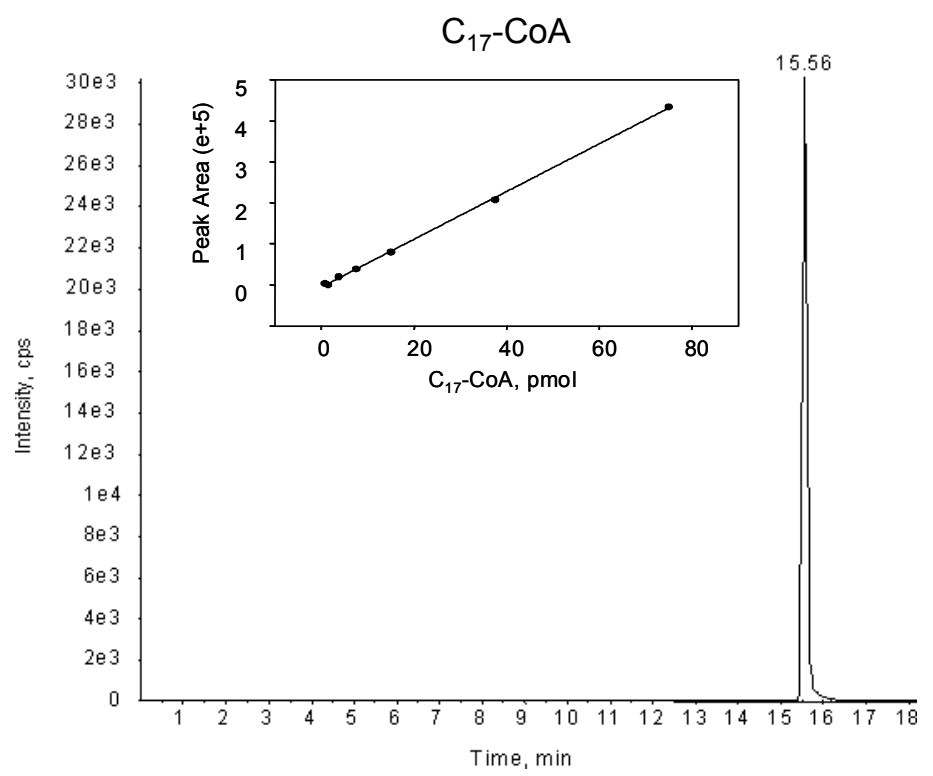

D)

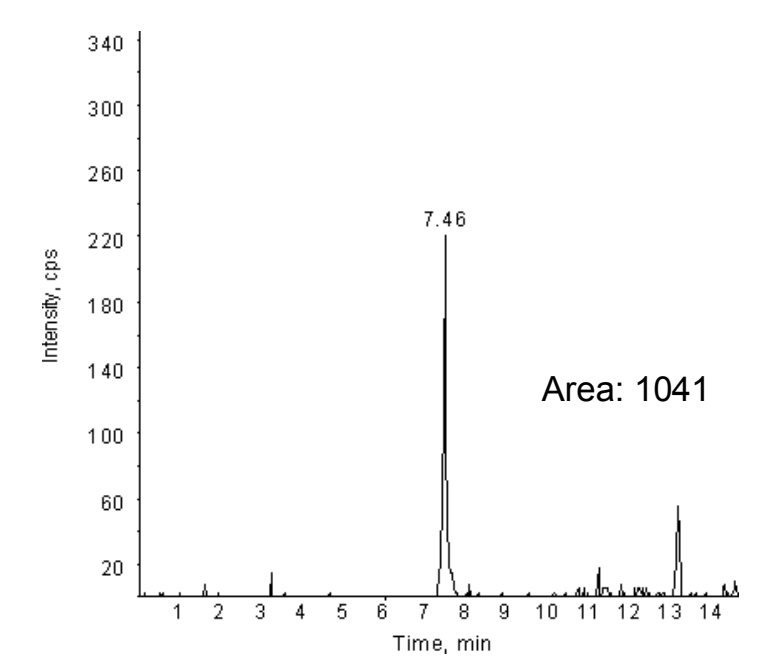


FIGURE 6

A)

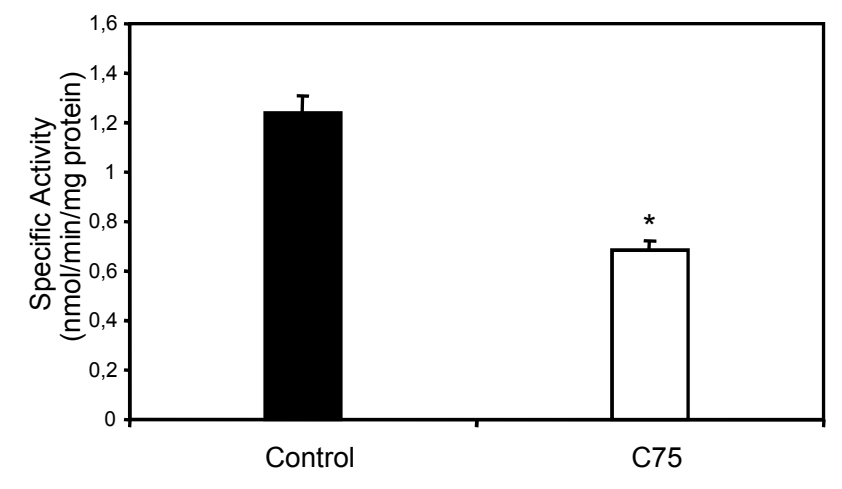

B)

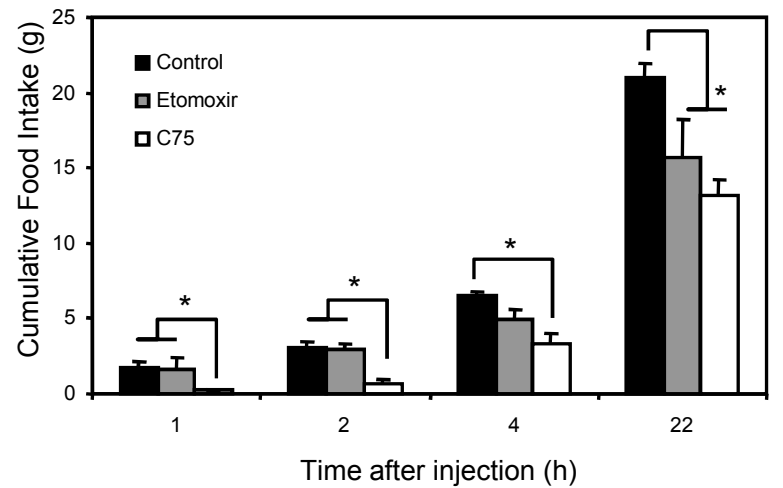

C)

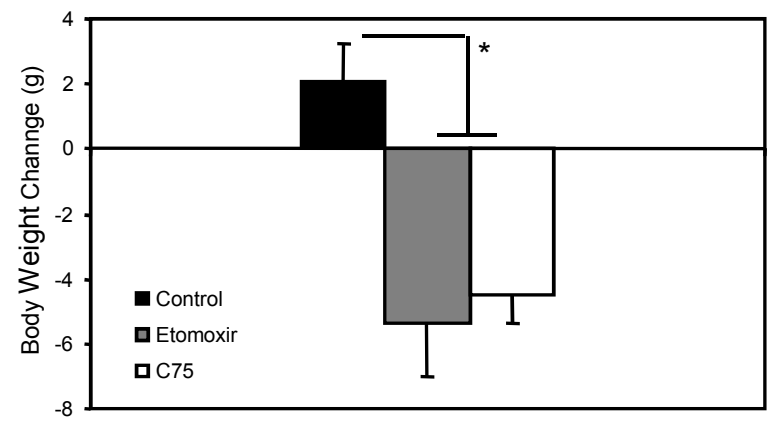

Time after injection (22 h) 
FIGURE 7

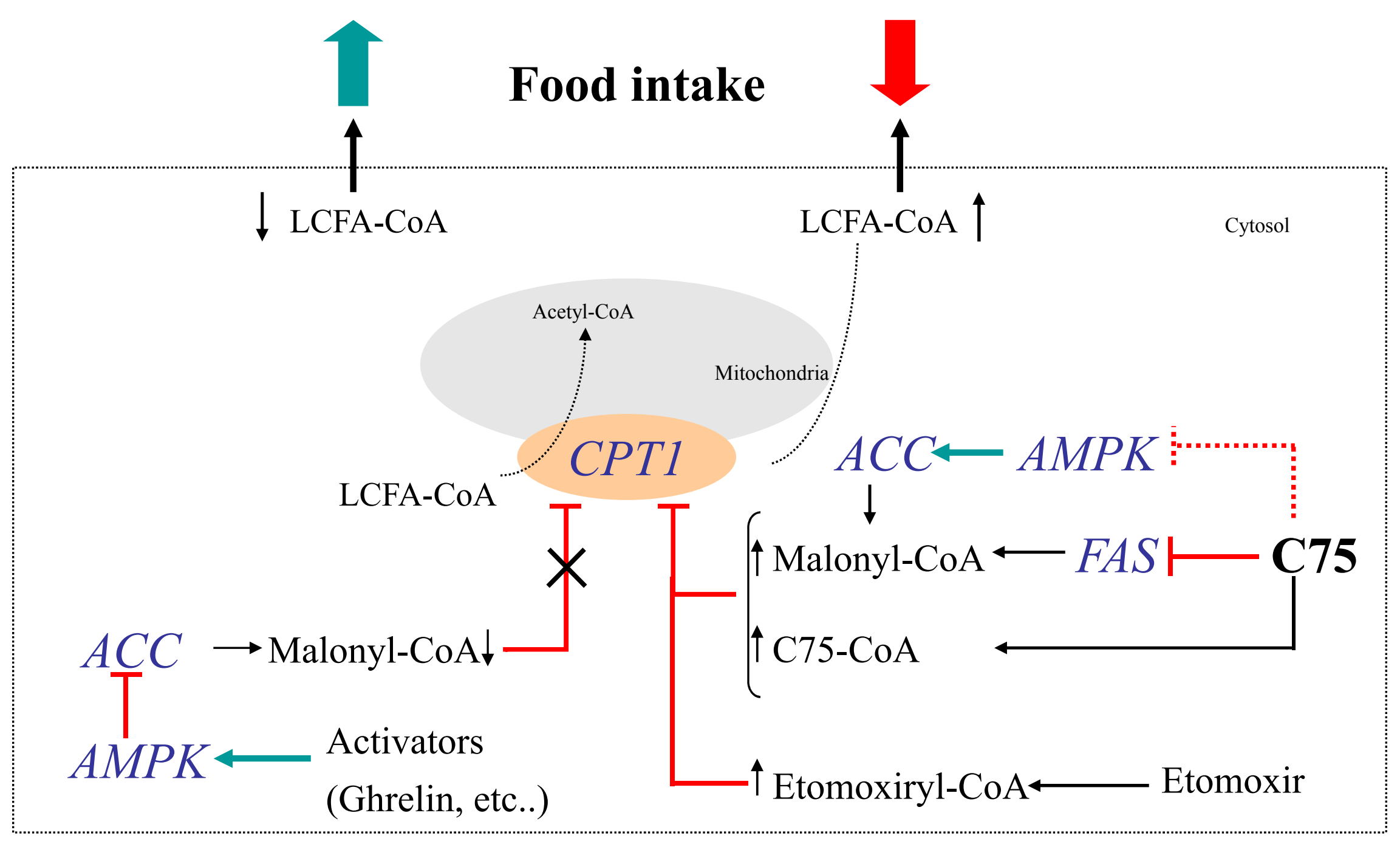

Estimulation

Inhibiton

$-1$ 